\title{
Withdrawal from glucocorticosteroid therapy: clinical practice recommendations
}

\author{
Crésio Alves, ${ }^{1}$ Teresa Cristina Vicente Robazzi, ${ }^{2}$ Milena Mendonça $^{3}$
}

\begin{abstract}
Objective: To present an up-to-date and practical review of how to safely withdraw glucocorticosteroid therapy.

Sources: A review of the published literature identified by searching the MEDLINE and LILACS databases (1997-2007), selecting the most representative articles on the subject.

Summary of the findings: Three clinical situations may occur during glucocorticoid withdrawal: adrenal insufficiency secondary to negative feedback on the hypothalamic-pituitary adrenal (HPA) axis, steroid withdrawal syndrome and relapse of the disease for which the glucocorticoids were prescribed. Although there is no consensus on how to best discontinue prolonged glucocorticosteroid therapy, there is agreement that this withdrawal should be gradual. This article updates pediatricians on how to recognize these problems and provides recommendations on how to safely suspend glucocorticosteroid therapy. A brief review of the pharmacology of glucocorticoids is also presented.

Conclusion: There is no good predictive test for predicting the risk of adrenal insufficiency in patients who have been on corticosteroid therapy chronically. There is a need for prospective studies to assess the true incidence of this problem and to propose rational strategies for preventing it. The current recommendation is that patients who have been on chronic and/or high dose glucocorticoids should be administered glucocorticoids during stress situations unless the integrity of the HPA axis has been established by dynamic tests.
\end{abstract}

J Pediatr (Rio J). 2008;84(3):192-202: Adrenal insufficiency, Cushing's syndrome, steroid withdrawal therapy, corticosteroid.

\section{Introduction}

Since their introduction to clinical practice, 60 years ago, corticosteroids have been widely used for the treatment of a great variety of diseases and they are the most powerful of all known anti-inflammatory agents. ${ }^{1,2}$ Their use has considerably reduced morbidity and mortality among people with serious conditions, such as autoimmune diseases, allergic processes, organ transplantation, adrenal insufficiency, congenital adrenal hyperplasia, and others. ${ }^{3-5}$ Nevertheless, when treatment is prolonged and/or corticosteroid doses are high, in addition to the significant side-effects associated with treatment (Cushing's syndrome), suspension or withdrawal in an inappropriate manner can cause three complications: secondary adrenal insufficiency due to suppression of the hypothalamus-pituitary-adrenal axis (HPA), steroid withdrawal or deprivation syndrome and reactivation of the underlying disease. ${ }^{1,6}$

In view of the large number of pediatric patients who are prescribed treatment with corticosteroids, the objective of this article is to provide an up-to-date and practical review of how to safely suspend corticosteroid therapy when patients have been on it for long periods or at high doses. In order to accomplish this the physiology and pharmacology of corticosteroids will be briefly reviewed, describing the principal syndromes associated with their withdrawal. The literature review was based on searches of the MEDLINE and LILACS databases,

1. Doutor. Professor e Coordenador, Residência em Endocrinologia Pediátrica, Departamento de Pediatria, Faculdade de Medicina, Universidade Federal da Bahia (UFBA), Salvador, BA, Brazil.

2. Mestre. Professora, Departamento de Pediatria, Faculdade de Medicina, UFBA, Salvador, BA, Brazil. Membro, Departamento Científico de Reumatologia, Sociedade Brasileira de Pediatria.

3. Acadêmica de Medicina, UFBA, Salvador, BA, Brazil.

No conflicts of interest declared concerning the publication of this article.

Alves C, Robazzi TC, Mendonça M. Withdrawal from glucocorticosteroid therapy: clinical practice recommendations. J Pediatr (Rio J). 2008;84(3):192-202.

Manuscript received Nov 13 2007, accepted for publication Jan 082008.

doi:10.2223/JPED.1773 
selecting the most current and most representative articles on the subject published between 1997 and 2007, and also text books on the subject.

\section{The physiology of corticosteroids}

The adrenal gland is made up of two functional units: the medulla and the cortex. The hormones adrenaline and noradenaline are produced in the medulla. The adrenal cortex accounts for $90 \%$ of the gland, surrounding the centrally-located medulla. Histologically, the adrenal cortex is subdivided into the zona glomerulosa, the zona fasciculata and the zona reticularis, which produce three classes of hormones: mineralocorticoids, glucocorticoids and androgens. ${ }^{7}$ The zona fasciculata is responsible for the synthesis of glucocorticoids, of which group cortisol (hydrocortisone) is the primary representative. Cortisol secretion is controlled by corticotrophin or adrenocorticotrophic hormone (ACTH), which is secreted by the anterior pituitary, which in turn is regulated by a hypothalamic hormone, corticotrophin-releasing hormone (CRH). ${ }^{8}$ Both ACTH and $\mathrm{CRH}$ are controlled by cortisol through a feedback mechanism, i.e., the greater the plasma cortisol concentration, the less ACTH and CRH are released, and the lower the serum cortisol levels, the greater the amount of ACTH and CRH that is released. The HPA axis exhibits a circadian or nyctohemeral rhythm. In individuals with a normal sleep/wake rhythm, the highest concentrations of $\mathrm{ACTH}$ and cortisol occur during the early morning, at 6 and 8 am respectively, decreasing during the afternoon ( $50 \%$ of the morning level by $4 \mathrm{pm}$ ) and reaching their lowest levels at around midnight. ${ }^{9}$ In addition to these endocrinal stimuli, cortisol secretion is also regulated by neural stimuli originating in the central nervous system and triggered by stressful situations, which explains the elevated serum cortisol levels observed in these situations. ${ }^{8}$

Once in circulation, $75-80 \%$ of the cortisol binds with a transport protein, an alpha-globulin called transcortin or cortisol binding globulin (CBG). Only a small fraction (6\%) exists as a free hormone, and passes through cell membranes binding to specific plasma receptors. ${ }^{10}$ The hormone-receptor complex enters the nucleus where it will stimulate, suppress or influence the process of protein synthesis by means of interaction with DNA (genomic action) or with proteins involved in the transcription process (non-genomic action). ${ }^{8,11} \mathrm{~A}$ third mechanism which was not dependent on intra-nuclear action could explain the rapid action of some corticosteroids, which supports their use for pulse therapy. ${ }^{9}$ Cortisol is metabolized by the hepatic cells and its products, more polar and water-soluble, are excreted by the liver and kidneys. ${ }^{7}$ Preliminary research had reported that, in normal adults who are not under stress, the adrenal gland secretes an average of 20 $\mathrm{mg} /$ day of cortisol. ${ }^{12}$ However, recent studies have indicated that the level of production is lower still, at around $5-7 \mathrm{mg} / \mathrm{m}^{2}$ / day, or approximately $8-15 \mathrm{mg} /$ day. ${ }^{11,13,14}$ This level of secretion is the equivalent to approximately $10-12 \mathrm{mg} / \mathrm{m}^{2} /$ day of hydrocortisone administered orally, compensating for the incomplete bioavailability resulting from intestinal absorption and hepatic metabolism. ${ }^{14-16}$

\section{The pharmacology of corticosteroids}

Synthetic corticosteroid analogues are produced by means of structural modifications to their basic molecule that are intended to emphasize specific pharmacological actions. ${ }^{17}$ The many different types of corticosteroids and their pharmacological preparations vary in terms of their glucocorticoid mineralocorticoid and anti-inflammatory power. However, their tendency to cause adrenal depression is correlated with their glucocorticoid activity.

Cortisol is considered the basis of reference for analyzing glucocorticoid activity, and is given a value of 1 , while dexamethasone, the most powerful, is rated at 25 , based on the classic, or genomic, mechanism of action. Therefore, if cortisol (hydrocortisone) is being given at $20 \mathrm{mg} / \mathrm{day}$, then the dexamethasone dose needed to achieve similar effects will be 25 times smaller or $0.8 \mathrm{mg} / \mathrm{day}^{1}{ }^{1}$ The mineralocorticoid action is related to the maintenance of electrolytic balance in the extracellular fluid, primarily determining water and sodium retention, potassium depletion and metabolic alkalosis. These effects occur after corticosteroids have bound to type 1receptors in renal cells, which, in turn, bind to aldosterone. ${ }^{17}$ Dexamethasone is the only glucocorticoid that has been shown not to have mineralocorticoid activity.

Corticosteroids are divided into three groups depending on the duration of ACTH suppression caused by a standard dose (equivalent to $50 \mathrm{mg}$ of prednisone): short action (hydrocortisone, cortisone, deflazacort), which suppress ACTH for less than 36 hours; intermediate action (triamcinolone, prednisone, prednisolone, methylprednisolone), which suppress ACTH for around 48 hours; and prolonged action (dexamethasone, betamethasone), which suppress ACTH for more than 48 hours. The variation in the duration of effect is not directly correlated with the plasma mean life of each hormone. For example, cortisol and dexamethasone, with similar plasma half lives of 90 and 100 minutes, have very different biological mean lives (in tissue), 8-12 hours for cortisol and 36-54 hours for dexamethasone.

The side effects of corticosteroids are related to the type of preparation, the time of day, dosage, duration, regime and route of administration, age and sex, underlying disease, concomitant use with other medications which could interfere with their action and individual sensitivity profiles. ${ }^{17}$ Different individuals suffer a heterogeneous range of adverse effects from the same dose of corticosteroid, probably due to kinetics, different plasma concentrations of transport proteins used by these medications and differences in clearance. ${ }^{18}$ Reduced clearance are observed in liver patients and nephropathies with estrogen, ketoconazole and anti-inflammatory use. In 
Table 1 - Risk factors for suppression of the hypothalamic-pituitary-adrenal axis in patients given corticosteroid therapy

\begin{tabular}{ll}
\hline Greater risk of suppression of the HPA & Lesser risk of suppression of the HPA \\
\hline Treatment dose & Maintenance dose \\
Split doses & Single dose \\
Nighttime doses & Morning doses \\
Daily doses & Doses on alternate days \\
Long action corticosteroids & Short action corticosteroids \\
Systemic use & Topical use \\
Prolonged use & Short-term use
\end{tabular}

HPA = hypothalamic-pituitary-adrenal axis.

contrast, clearance can be accelerated in patients on phenytoin, phenobarbital or rifampicin. ${ }^{18}$

\section{Syndromes associated with corticosteroid withdrawal}

Rapid reduction or abrupt withdrawal of corticosteroid therapy that has been prolonged or at high doses can cause three problems: secondary adrenal insufficiency (suppression of the HPA axis), steroid withdrawal or deprivation syndrome and relapse of the underlying disease for which the treatment had been prescribed. ${ }^{5,18-20}$ Table 1 lists the principal risk factors related to occurrence of the syndromes associated with corticosteroid withdrawal.

\section{Secondary adrenal insufficiency (suppression of the HPA axis)}

The most feared complication of abrupt withdrawal of prolonged or high-dose corticosteroid therapy is suppression of the HPA axis, which leads to secondary adrenal insufficiency. ${ }^{16,21}$ Suppression may be partial or total, as a result of atrophy of the adrenal glands. ${ }^{6}$ Since there is a great deal of individual variability in susceptibility to suppression of the HPA axis after use of exogenous corticosteroids, it is not possible to predict with confidence which patients will be affected even when factors such as dose and duration of corticosteroid therapy are taken into account. ${ }^{22-24}$ Therefore, its true prevalence remains unknown. Some studies have considered it to be fairly infrequent due to the fact that physicians are taught to gradually reduce corticosteroid doses, thereby allowing the HPA axis activity to recover. ${ }^{22-25}$ However, recent reports have indicated that incorrect withdrawal of corticosteroids from patients who have been on them for prolonged periods is the primary cause of adrenal crises and secondary adrenal insufficiency. ${ }^{26,27}$

The symptomology of chronic adrenal insufficiency is characterized by anorexia, nausea, vomiting, abdominal pain, weakness, tiredness, asthenia, prostration, myalgia, arthralgia, weight loss, postural hypotension, somnolence and depression. ${ }^{14}$ The hyperpigmentation of skin and mucosas that is typical of Addison's disease is not present, since pituitary secretion of ACTH is inhibited. ${ }^{1,14,28}$ Some patients may exhibit hypoglycemia. Hyponatremia and hyperkalemia are uncommon because ACTH suppression has a minimal effect on aldosterone secretion. ${ }^{11,29}$ In severe cases, an acute adrenal crisis may occur (vomiting, diarrhea, fever or hypothermia, acute dehydration, hypotension, hypoglycemia, shock and coma), which is a life-threatening situation.

Acute adrenal insufficiency is treated with volume replacement associated, if in shock, and administration of intravenous hydrocortisone at doses of $50-200 \mathrm{mg} / \mathrm{m}^{2} /$ day, every 6 hours.

\section{Steroid withdrawal or deprivation syndrome}

When a patient is unable to tolerate withdrawal of a glucocorticoid, in the absence of an acute relapse of the underlying disease subjacent and in the absence of HPA axis suppression, they are defined as having steroid withdrawal syndrome. ${ }^{18,19,30}$ Clinical status is characterized by physical or psychological dependence. ${ }^{31}$ Physical dependence is characterized by anorexia, nausea, vomiting, weight loss, asthenia, headache, myalgia, arthralgia, postural hypotension, tachycardia, fever and flaky skin. 5,18,30,32 Psychological dependence can manifest as variable degrees of adverse psychological effects. Mood swings and emotional lability are the most common manifestations, followed by delirium and psychotic states. Children and adolescents are also vulnerable to the effects of the steroid withdrawal syndrome, which can occur even when the medication is still being given at supraphysiological levels. 6,33,34

The mechanisms responsible for steroid withdrawal syndrome are not yet certain. Nevertheless, it is thought that several mediators may be involved, including $\mathrm{CRH}$, vasopressin, proopiomelanocortin, cytokines (interleukin 1 and 6, tumor necrosis factor alpha) prostaglandins (phospholipase A2) and also changes to the noradrenergic and dopaminergic systems. ${ }^{19,30}$ 
Table 2 - Recovery of the hypothalamic-pituitary-adrenal axis after suspension of chronic corticosteroid therapy (modified from Graber et al. ${ }^{38}$ )

\begin{tabular}{lccc}
\hline Time in months & Morning baseline serum cortisol & Baseline serum ACTH & HPA axis stimulation test \\
\hline $0-1$ & $\downarrow$ & $\downarrow$ & Abnormal \\
$2-5$ & $\downarrow$ & Normal or $\uparrow$ & Abnormal \\
$6-9$ & Normal & Normal & Abnormal \\
$>9$ & Normal & Normal & Normal \\
\hline
\end{tabular}

$\downarrow=$ serum concentration reduced; $\uparrow=$ serum concentration increased.

Diagnosis is established by demonstrating HPA axis integrity in the presence of symptoms that would suggest adrenal insufficiency. ${ }^{6}$ The syndrome is self-limiting, with a duration that varies from 6 to 10 months, and can be easily treated with a temporary increase in corticosteroid dose, followed by slow withdrawal. ${ }^{19}$

\section{Relapse of the underlying disease}

Recrudescence of the underlying disease is diagnosed based on reappearance of the manifestations of the illness that was being treated with corticosteroids. Taking juvenile idiopathic arthritis as example, withdrawal of corticosteroid therapy should be gradual, and physicians should be alert for signs and symptoms that could indicate reactivation of the disease, such as signs of joint inflammation, fever, hepatosplenomegaly, adenomegaly or increased values in the results of tests for inflammatory activity, which, if they emerge during the process of withdrawal from corticosteroids, may indicate a need to increase doses once more. ${ }^{17,35,36}$

\section{Assessing recovery of the hypothalamus-pituitary-adrenal axis}

Identification of individuals suffering from suppression of the HPA axis caused by corticosteroid therapy is extremely important since this condition can lead to the development of adrenal insufficiency if the patient is subjected to stressful situations. Since the symptomology of adrenal insufficiency is not specific, it must be documented through laboratory test results. ${ }^{6,37}$ Graber et al., ${ }^{38}$ in 1965 , studied recovery of the HPA axis in chronic corticosteroid users, demonstrating that the first parameter to normalize was baseline ACTH (after 2-5 months), followed by baseline serum cortisol (after 6-9 months) and finally cortisol after stimulation with ACTH (after 9 months) (Table 2).

Tests not involving stimulation, such as measurement of ACTH and of morning serum and saliva cortisol and assays of free cortisol in urine, have limited sensitivity for diagnosing secondary adrenal insufficiency, but they can be carried out before running stimulus tests in order to verify whether baseline levels have already returned to normal, ACTH first, followed by cortisol. ${ }^{21}$
Measuring morning ACTH in serum is not of use for assessing adrenal insufficiency because the precision of these assays is limited for low values and because morning ACTH serum levels are lower in children than in adults (5-20 vs. 20-80 $\mathrm{pg} / \mathrm{mL}$ ), making it difficult to differentiate between normal low values and those that are the result of a true case of HPA axis suppression. ${ }^{28}$

Determination of baseline morning cortisol in serum (before 9 hours in the morning) suggests adrenal insufficiency induced by corticosteroid therapy when levels are below $3-5 \mathrm{mcg} / \mathrm{dL}$ and suggests normal adrenal function when values are greater than $20 \mathrm{mcg} / \mathrm{dL}^{6,32}$ Intermediate values indicate a need for other forms of assessment, since physiological variables such as changes to transcortin concentration, puberty, exercise and even emotional stressors as subtle as anticipation of an injection, can influence the results. ${ }^{28}$ In other words, this test is only of use when the results are at the extremes of normality. ${ }^{32}$ It is important that cortisol assays (baseline or post-stimulation) be carried out after suspension of corticosteroid therapy, or at least 24 to 48 hours after the last dose, since, with the exception of dexamethasone, the other corticosteroids interfere with the results. ${ }^{6,39}$

Measurement of free cortisol in saliva, a noninvasive and easy to obtain method, has not yet been validated for assessing the HPA axis, due to technical difficulties with the tests and due to the need to control variables that interfere with results (for example, nutritional intake, medications). 40,41 Recently, Silva et al. used this method to assess the HPA axis in Brazilian children aged 45 days to 36 months, establishing reference values that will be useful to studies that investigate adrenal insufficiency in the future. ${ }^{42}$

Determination of free cortisol in 24-hour urine is not indicated for assessing lack of HPA axis function since less than $1 \%$ of free cortisol is excreted in urine. ${ }^{28}$ Therefore, this test is more used to assess hypercortisolism, which is a situation in which transcortin saturation occurs, thereby making increased excretion of free cortisol in urine possible.

For these reasons, inhibition and recovery of the HPA axis is best assessed by means of challenge tests (insulin, metyrapone, $\mathrm{CRH}, \mathrm{ACTH}$ ) or, in some cases, during situations involving clinical stress, such as surgery, trauma or severe 
infection. 5,6,10,32 Despite the difficulty in interpreting tests to assess HPA axis function due to the inability to relate biochemical evidence of suppression with its clinical significance, these tests continue to be the only objective data that are available to assess HPA axis recovery and should be analyzed with great care. ${ }^{32}$

The insulin tolerance test $(0.1-0.15 \mathrm{UI} / \mathrm{kg}$ of intravenous regular insulin, assaying serum cortisol and glycemia at baseline and at 60 minutes; normal response: cortisol $>18 \mathrm{mcg} /$ $\mathrm{dL}$, assuming that glycemia is $<45 \mathrm{mg} / \mathrm{dL}$ or less than $50 \%$ baseline) which mimics a severe stress, has been abandoned due to the risk of hypoglycemic and hypokalemic convulsions after treatment with glucose solution. ${ }^{14,23,43}$ The metyrapone test $(30 \mathrm{mg} / \mathrm{kg}$, oral metyrapone at midnight, measuring serum 11-deoxycortisol and cortisol next morning; normal response: 11 -deoxycortisol $>5 \mathrm{mcg} / \mathrm{dL}$ and cortisol $>7 \mathrm{mcg} /$ $\mathrm{dL}$ ) is based on suppression of 11-beta-hydroxylase, an enzyme that converts 11 -deoxycortisol to cortisol. ${ }^{14,23}$ In a normal individual, ACTH and 11-deoxicortisol will increase, while in patients with HPA axis suppression, this increase will not occur. ${ }^{28}$ Although this is an excellent test, its use is limited by the difficulty involved in obtaining the medication and the risk of precipitating an adrenal crisis. ${ }^{14}$ The $\mathrm{CRH}$ test (1 $\mathrm{mcg} / \mathrm{kg}$, rapid intravenous $\mathrm{CRH}$, assaying serum cortisol at baseline and after 30 minutes; normal response: cortisol increases 3-4 times over baseline) is not widely used due to its high cost, side effects and absence of superiority in relation to other available methods. ${ }^{14,23}$

For these reasons, the ACTH stimulus test (Cortrosina ${ }^{\circledR}$, Synacthen ${ }^{\circledR}$ ) carried out with low doses (1 mcg) or high doses (250 $\mathrm{mcg}$ ) is the most often used dynamic examination, despite ongoing discussions related to the fact that it only assesses adrenal function, rather than providing information on the integrity of the HPA axis. ${ }^{39}$ Although the low, "more physiological" dose has been described as being more sensitive than the high dose (standard), ${ }^{14,44}$ it is little used due to the need for dilution and because it is unfamiliar to physicians. $^{37}$

The stimulus test with high doses of ACTH is carried out as follows: after withdrawal of corticosteroid therapy for at least 24 hours, morning baseline serum cortisol is assayed at 7-8 am (reference value: $5-25 \mathrm{mcg} / \mathrm{dL}$ ), $250 \mathrm{mcg}$ of synthetic ACTH is administered intravenously and, after 30 and 60 minutes, serum cortisol is assayed again. ${ }^{6,11,44}$ The normal response is that after the stimulus cortisol rises to $20 \mathrm{mcg} / \mathrm{dL}$ or increases more than $10 \mathrm{mcg} / \mathrm{dL}$ with relation to baseline. ${ }^{3,21}$ This test is almost always positive in patients with secondary adrenal insufficiency of longer duration or greater severity, although false-negative results can be observed among those with recent or mild disease, since the adrenal glands respond to the supraphysiological doses of $\mathrm{ACTH}{ }^{22,44}$ Therefore, negative tests do not rule out the possibility of secondary adrenal insufficiency and clinical reassessment is necessary, with additional tests being indicated if the suspicion remains, generally using metyrapone or insulin. ${ }^{21,44}$ When ACTH test results are normal, it can be considered that HPA axis recovery has been reestablished. ${ }^{32}$ Alternatively, if it is not possible to carry out the ACTH test, patients who have used corticosteroids for prolonged periods can be considered at risk of adrenal insufficiency up to 1 year after their withdrawal. ${ }^{1,3,6,37}$

\section{Planning for withdrawal of corticosteroid therapy}

Successful suspension of corticosteroid therapy can be described as that which results in a rapid transition from a state of tissue hypercortisolism to a state of total exogenous corticosteroid deprivation without resurgence of the underlying disease and without adrenal insufficiency or corticosteroid dependency emerging. ${ }^{1}$ Unfortunately, published studies are limited with respect to predicting which patients will develop adrenal insufficiency after prolonged corticosteroid therapy. The principal variables that affect this analysis are: age, individual variability, underlying disease, type of corticosteroid, route of administration and duration of treatment.

Due to these limitations, when planning withdrawal of corticosteroid therapy, it is prudent to start from the assumption that the HPA axis will be suppressed. Four basic questions should be answered before initiating corticosteroid withdrawal, as will be shown below.

\section{What is the underlying disease for which the corticosteroids are being used?}

The majority of patients who exhibit difficulties with withdrawal of corticosteroid therapy are suffering from severe hematological, inflammatory or immunological diseases. Therefore, the treating physician must be aware of which signs and symptoms indicate recrudescence of the subjacent disease, which in turn will provide information on speed of corticosteroid withdrawal, or even whether temporary dosage increases will be necessary. If, on the other hand, there is no underlying disease to be treated, such as, for example, in situations where a corticosteroid was used to treat an allergic reaction which has already been resolved, the anti-inflammatory dosage can be abruptly reduced to a physiological dose without risk of adrenal insufficiency. ${ }^{9}$

\section{What are the reasons for starting and discontinuing corticosteroid therapy?}

The reasons for initiating treatment with corticosteroids vary greatly, due to the multiple therapeutic uses of this class of drugs. Withdrawal is considered when their use is no longer recommended or when significant side-effects appear. Exacerbation of herpetic keratitis is one of the rare contraindications to continuation of corticosteroid therapy. ${ }^{1}$ Other conditions in which withdrawal of corticosteroid therapy should be considered: hard to control diabetes mellitus, severe hypertension, incapacitating osteoporosis, cerebral 
pseudotumor, accentuated growth restriction, corticosteroid-induced psychosis and peptic ulcer. ${ }^{1,12,29}$

The decision to discontinue corticosteroids is the result of weighing up the benefits of continuation against the severity of the adverse effects. There is no simple rule that can be applied to all cases.

\section{Which corticosteroid is being used, for how long, at what dose, via which route of administration and under what therapeutic regime?}

Patients given the long acting preparations, high doses, over prolonged periods, via oral or parenteral routes and at higher frequencies of administration are at greater risk of developing the complications associated with glucocorticoid withdrawal. ${ }^{3}$

Long acting preparations have a longer tissue life, which induces a chronic state of tissue hypercortisolism, making suppression of the HPA axis more likely.

With relation to duration of corticosteroid therapy, there is no consensus on the definition of acute corticosteroid therapy. The literature uses durations varying from 7 to 14 days. $^{3}$

In normal individuals, physiological doses of corticosteroids are equivalent to a dose of $6-8 \mathrm{mg} / \mathrm{m}^{2} /$ day of intravenous hydrocortisone, or $10-15 \mathrm{mg} / \mathrm{m}^{2} /$ day taken orally. ${ }^{9}$ For adults, a high daily dosage is defined as when corticosteroid posology is greater than $20-40 \mathrm{mg} /$ day of prednisone or equivalent. ${ }^{12,37}$ The term "alternate doses" describes the use of corticosteroids every 48 hours.

Administering corticosteroids in several different doses during the day makes HPA axis suppression more probable. In the same manner, prescribing a single dose at night, on retiring, will inhibit peak $\mathrm{ACTH}$ secretion during the early morning, resulting in greater adrenal suppression. ${ }^{1}$ Whenever possible, intermediate or long acting corticosteroids (for example, prednisone, prednisolone and dexamethasone) should always be taken in a single dose during the morning. Short acting preparations, such as hydrocortisone and cortisone acetate, can be taken in two doses, on waking and late afternoon, splitting the total dose into $2 / 3$ in the morning and $1 / 3$ in the afternoon. ${ }^{6}$

Although corticosteroids administered via systemic routes, particularly parenterally, are responsible for more complications, this is not the only regime to cause adrenal insufficiency. ${ }^{40}$ Other routes of administration (transdermal, intranasal, inhalation, intra-ocular and intra-articular) can also cause of systemic effects, depending on the quantity of the drug that reaches the circulation. ${ }^{14}$ Dermatological corticosteroid therapy for prolonged periods, or when used over a large proportion of the body surface area, can cause HPA axis suppression. ${ }^{3}$ The same can occur when intranasal corticosteroids are used for prolonged periods or in high doses. ${ }^{45}$ Lima et al. (2002) described a patient with adrenal suppression after nasal dexamethasone use who took 15 months to return to normal. ${ }^{46}$ When there is a need to use inhaled or intranasal corticosteroids, care should be taken to choose those with greater hepatic clearance and, therefore, less systemic bioavailability. Examples of such corticosteroids, in decreasing order of strength, are: fluticasone $=$ mometasone $>$ budesonide $=$ beclomethasone $>$ triamcinolone $=$ flunisolide. ${ }^{46,47}$

\section{Does the patient have cushingoid features?}

Patients with cushingoid symptomology due to corticosteroid therapy will probably have a suppressed HPA axis and adrenal atrophy, requiring greater care with withdrawal of the corticosteroid. ${ }^{1}$

\section{Corticosteroid therapy withdrawal regimes}

There are several regimes for withdrawing corticosteroid therapy, although there are no consensus documents, directives or controlled clinical trials to provide guidance on how to proceed with withdrawal. In clinical practice, the majority of the physicians who prescribe corticosteroids develop their own withdrawal regimes on an empirical basis. ${ }^{6,22}$ What all of them have in common is that withdrawal should never be abrupt.

In general, patients given acute corticosteroid therapy (< 7-14 days) do not develop HPA axis suppression. Therefore, treatment can be suspended with no need for any type of reduction regime. ${ }^{1,12,48,49}$

Where therapy has been chronic, the objective is to rapidly reduce the therapeutic dose to a physiological level and then proceed with slower withdrawal thereafter in order to permit the HPA axis to recover. In this situation patients can be divided into two groups: with and without underlying diseases. The category of chronic therapy with underlying disease includes individuals with severe diseases who have been using high doses of corticosteroids for prolonged periods. Before initiating withdrawal of corticosteroid therapy, it is recommended that all available clinical, biochemical and laboratory data on the activities status of the subjacent disease be collected in order that signs of resurgence can be promptly identified and, if necessary, the doses prescribed can be increased. Patients who have been using corticosteroids for "prolonged" periods and whose underlying disease has been resolved can have their therapeutic dosage reduced to a physiological dose more quickly since there is no risk of further acute occurrences of the symptoms that prompted the drug to be prescribed. Irrespective of group (chronic therapy with or without underlying disease), if corticosteroid withdrawal or adrenal insufficiency symptomology appear, the dose being used at the time should be elevated or maintained for longer.

Kountz \& Clark $^{3}$ recommend reducing corticosteroids gradually until a dose of $5 \mathrm{mg} /$ day of prednisone or equivalent is reached. The patient will then remain on this dosage for 4 weeks, after which period the ACTH test will be used. If 
Table 3 - Corticosteroid therapy withdrawal regime, based on duration of treatment and presence or absence of an underlying disease

Acute treatment $(<7-14$ days)

Corticosteroid therapy can be withdrawn in a single step with no need for a reduction regime.

Chronic treatment with no underlying disease

Substitute corticosteroids with prolonged action $\rightarrow$ intermediate action $\rightarrow$ short action.

Modify multiple doses per a posology to single morning doses.

Change from daily use to alternate days.

Reduce the dose by around $20 \%$ every 2-4 days until a physiological dose is reached. Next, reduce to half the physiological dose over $2-4$ weeks. After reaching half the physiological dose ( $5-6 \mathrm{mg} / \mathrm{m}^{2} /$ day of hydrocortisone or $1-1.5 \mathrm{mg} / \mathrm{m}^{2} / \mathrm{day}$ of prednisone), morning serum cortisol and ACTH should be assayed monthly, until they reach normal levels. When baseline morning serum ACTH and cortisol are normal, discontinue the corticosteroid and carry out the rapid ACTH stimulus test monthly until post-stimulation cortisol response is normal (post-stimulus level $>20 \mathrm{mcg} / \mathrm{dL}$ or $>10 \mathrm{mcg} / \mathrm{dL}$ greater than baseline). When this point is reached, it can be considered that the HPA axis has recovered.

Alternatively, when the laboratory tests above cannot be carried out, patients who have used corticosteroids for prolonged periods can be considered as having suppression of the HPA axis up to 1 year after suspension of corticosteroid therapy.

Chronic treatment with underlying disease

The regime is similar to that for chronic treatment without underlying disease, with the following differences:

The velocity of reduction is dependent on the underlying disease. For example: $10 \%$ per week;

If there are signs of resurgence of the underlying disease, return to the previous dose.

Continue reducing within the limitations imposed by the disease, until the ACTH test is normal.

$\mathrm{ACTH}=$ adrenocorticotrophic hormone; HPA = hypothalamus-pituitary-adrenal axis.

the response is abnormal, the dose should be modified to 5 $\mathrm{mg}$ on alternate days and the $\mathrm{ACTH}$ test repeated until normalization occurs. With this regime, any stressful situations should be treated by increasing the corticosteroid dose to 25-300 mg/day of hydrocortisone or equivalent. ${ }^{3}$

Table 3 illustrates the reduction regime used at our center. It is important to be aware that not every patient will need an increased dose in stressful situations. For example, a patient on $50 \mathrm{mg} / \mathrm{m}^{2} /$ day of hydrocortisone or equivalent, will not need an increased dose in cases of mild or minimal stress, since the dose being used already "covers" such stress situations. On the other hand, a patient on physiological doses of hydrocortisone will need to increase their dose by three times for mild stresses, five times for moderate stresses and up to 10 to 15 times for severe stress.

\section{Corticosteroid supplementation in stressful situations}

Stress occurs as a result of the body's attempts to maintain homeostasis in the face of an adverse event, and the HPA axis and the sympathetic nervous system are the primary 
mediators of this response. Practically all forms of stress, whether physical or psychological, cause increased secretion of $\mathrm{ACTH}$, which is followed by a significant increase in blood cortisol levels (3-5 times in mild cases and 10-15 in severe cases). ${ }^{12,14}$ This increased cortisol production is the theoretical basis for supplementing corticosteroids to supraphysiological doses in patients with confirmed or presumed adrenal insufficiency who are subjected to stress. ${ }^{39}$ What level of serum cortisol might indicate an appropriate response is unknown as yet and would probably vary depending on the stress trigger event and HPA axis function. ${ }^{7}$

There are countless regimes for supplementing corticosteroids in stress situations. These recommendations are generally empirical and are not based on controlled clinical studies. ${ }^{14,40}$ The only point of consensus between them is that hydrocortisone is the corticosteroid of choice due to its mineralocorticoid action. Since prednisone needs to be converted to prednisolone and cortisone acetate needs to be converted to cortisol, by the action of the 11-beta-hydroxylase type I enzyme in the liver, before they have glucocorticoid action, neither of them are indicated for liver patients. ${ }^{11}$

Although the ideal regime (dose, frequency and duration) is subject to debate, the doses recommended currently are lower than have been prescribed in the past, taking into consideration the fact that excessive doses may lead to side effects, such as difficulties with healing, hyperglycemia, immunosuppression and water retention. ${ }^{39}$

One of the most often cited studies is a review published in 1994 by Salem et al., which bases its recommendations on different "degrees" of surgical stress, which have been adapted to their clinical equivalent in terms of severity. ${ }^{50}$ According to these authors, adolescents and adults should be given $25 \mathrm{mg}$ /day of hydrocortisone when subjected to surgical procedures considered of mild stress (inguinal herniorrhaphy, for example); 50-75 mg/day when subjected to moderate stress surgery (non-laparoscopic cholecystectomy, for example); and 100-150 mg/day when high stress surgery is carried out (heart surgery, for example). The hydrocortisone should be administered every 8 hours for 1 - 3 days, being withdrawn or returned to the normal dose as soon as the stress is removed. ${ }^{50}$ Another regime, also for adults, recommends doubling or tripling the glucocorticoid dose during mild to moderate stress, using $100-150 \mathrm{mg}$ of hydrocortisone via continuous venous infusion in the presence of severe stress or inability to use the oral route. ${ }^{6,16}$ Krasner recommends doubling or tripling the corticosteroid dose in situations of moderate stress. ${ }^{6}$ Although this recommendation is useful for patients on physiological doses, it is unnecessary for those on anti-inflammatory doses.

In a recent review, Shulman et al. recommend the following supplementation regime for the pediatric population: $30-50 \mathrm{mg} / \mathrm{m}^{2} /$ day of intravenous hydrocortisone, every 6 hours for moderate stress, and up to $100 \mathrm{mg} / \mathrm{m}^{2} /$ day for severe stress, for a period of $24-48$ hours, unless the situation causing the stress continues. ${ }^{14}$ Key et al. described a corticosteroid supplementation regime for surgical procedures of the oral cavity, in which patients on doses of over $10 \mathrm{mg} /$ day of prednisone will be given the following doses of hydrocortisone: $25 \mathrm{mg}$ intravenously before minor surgery (for example, single extractions); $25 \mathrm{mg}$ during induction + $100 \mathrm{mg}$ via continuous venous infusion, for 24 hours, for moderate surgery (for example, surgery of the mandible); and extending this to 48-72 hours, for major surgery (for example, head and neck surgery). ${ }^{51}$

However, not everyone agrees that supplementation with elevated corticosteroid doses in stress situations is always necessary, since there is no consensus on a definition of stress, nor on how to quantify its severity. Some authors postulate that, for patients with confirmed adrenal insufficiency, there is no indication for supplementary corticosteroid doses, beyond the usual dose, when stress is mild (for example, temperature $<38{ }^{\circ} \mathrm{C}$, upper airway infection, otitis media and immunization), as long as the patient is clinically healthy. ${ }^{14}$ Supporting these data, other studies indicate that corticosteroid supplementation during surgical stress has been overestimated and that maintenance of habitual corticosteroid doses may be sufficient for patients undergoing less severe surgical procedures. ${ }^{52}$

In the absence of evidence of HPA axis recovery in patients who have been on corticosteroids for prolonged periods, supplementation is recommended during situations of stress, such as, for example, fractures, surgery, trauma, labor, invasive dental procedures, severe systemic infections, major burns and where axillary temperature is $>38.5^{\circ} \mathrm{C} .{ }^{12}$

These patients should be instructed to carry some type of identification (worn around the neck or wrist or carried as a card) warning of their clinical status of corticodependence plus a medical report detailing the measures needed to treat it, including intramuscular hydrocortisone requirements. Stress dosages should be reviewed periodically so that adjustments can be made for increases in weight. Table 4 illustrates our center's recommendations for corticosteroid supplementation under different stress situations.

\section{Final comments}

Corticosteroid therapy is of fundamental importance in clinical practice. However, incorrect suspension or withdrawal of corticosteroids after prolonged treatment and/or high doses can be associated with several problems, such as adrenal insufficiency, steroid withdrawal symptom and reactivation of the underlying disease. Before proceeding to withdraw corticosteroid therapy, physicians should: 1) know how to identify which patients are at risk of developing the syndrome is associated with withdrawal; 2) know how to assess and prescribe withdrawal of the treatment, reducing the corticosteroid dosage gradually and in a manner adapted to each 
Table 4 - Corticosteroid supplementation in stress situations (adapted from Cooper \& Stewart, ${ }^{11} \mathrm{Goichot}^{\mathrm{et}}$ al. ${ }^{23}$ and Salem et al. ${ }^{50}$ )

\begin{tabular}{|c|c|c|c|}
\hline \multirow[b]{2}{*}{ Intensity of stress } & \multicolumn{2}{|c|}{ Example stress situations } & \multirow{2}{*}{$\begin{array}{l}\text { Supplementation } \\
\text { recommendation }^{+}\end{array}$} \\
\hline & Clinical & Surgical* & \\
\hline Minimum & $\begin{array}{l}\text { Immunization, coughing, cold } \\
\text { without fever }\end{array}$ & - & $\begin{array}{l}\text { Maintain physiological doses } \\
=10-12 \mathrm{mg} / \mathrm{m}^{2} / \text { day of } \\
\text { hydrocortisone, (OR, IM, every } 6 \\
\text { hours); or an equivalent dose of } \\
\text { another corticosteroid (OR, } \\
\text { every } 12 \text { hours) while the stress } \\
\text { lasts ( } 24-48 \text { hours). Afterwards, } \\
\text { return to habitual corticosteroid } \\
\text { dose. }\end{array}$ \\
\hline Mild & $\begin{array}{l}\text { Mild vomiting and diarrhea, } \\
\text { acute fever, mild traumatisms }\end{array}$ & $\begin{array}{l}\text { Single tooth extraction, small } \\
\text { areas of stitches, surgery under } \\
\text { local anesthetic }\end{array}$ & $\begin{array}{l}30-50 \mathrm{mg} / \mathrm{m}^{2} / \text { day of } \\
\text { hydrocortisone, (OR, IM, IV, } \\
\text { every } 6 \text { hours); or an equivalent } \\
\text { dose of another corticosteroid } \\
\text { (OR, every } 12 \text { hours) while the } \\
\text { stress lasts ( } 24-48 \text { hours). } \\
\text { Afterwards, return to habitual } \\
\text { corticosteroid dose. }\end{array}$ \\
\hline Moderate & $\begin{array}{l}\text { Significant vomiting and } \\
\text { diarrhea, reduced oral intake, } \\
\text { systemic infections, } \\
\text { temperature }>39^{\circ} \mathrm{C} \text {, fracture, } \\
\text { delivery }\end{array}$ & $\begin{array}{l}\text { Multiple tooth extraction, } \\
\text { umbilical herniorrhaphy }\end{array}$ & $\begin{array}{l}50-75 \mathrm{mg} / \mathrm{m}^{2} / \mathrm{day} \text { of } \\
\text { hydrocortisone, (IM, IV, every } 6 \\
\text { hours); or an equivalent dose of } \\
\text { another corticosteroid (IM, IV, } \\
\text { every } 12 \text { hours) while the stress } \\
\text { lasts ( } 24-48 \text { hours). Afterwards, } \\
\text { return to habitual corticosteroid } \\
\text { dose. }\end{array}$ \\
\hline Severe & $\begin{array}{l}\text { Septic shock, multiple trauma or } \\
\text { severe burns, multiple fractures, } \\
\text { severe and systemic infections }\end{array}$ & $\begin{array}{l}\text { Heart surgery, major surgery to } \\
\text { other organs and systems }\end{array}$ & $\begin{array}{l}100-150 \mathrm{mg} / \mathrm{m}^{2} / \text { day of } \\
\text { hydrocortisone, (IV, every } 6 \\
\text { hours, or in continuous venous } \\
\text { infusion) while the stress lasts } \\
\text { ( } 24-72 \text { hours). Afterwards, } \\
\text { return to habitual corticosteroid } \\
\text { dose, reducing the stress dose } \\
\text { by } 50 \% \text { a day. }\end{array}$ \\
\hline
\end{tabular}

IV = intravenous; IM = intramuscular; OR = oral.

* For surgery, one dose equivalent to the daily dose, via IV, should be administered before anesthetic induction and afterwards, following the recommendations above.

${ }^{+}$Doses equivalent to $50 \mathrm{mg} / \mathrm{m}^{2} /$ day (approximately four times the maintenance dose) of hydrocortisone are: dexamethasone (1.5 mg/m²/day), methylprednisolone $\left(10 \mathrm{mg} / \mathrm{m}^{2} /\right.$ day $)$, prednisolone $\left(12.5 \mathrm{mg} / \mathrm{m}^{2} /\right.$ day $)$.

patient; and 3) be aware that, where it is not possible to assess HPA axis integrity, all patients who have received prolonged treatment and/or with high doses should be considered at risk until 1 year after suspension of corticosteroid therapy.

It is extremely important that patients and their parents or guardians are correctly educated and instructed, in writing, about possible signs and symptoms during withdrawal and about corticosteroid supplementation during stress situations, and also that they understand and cooperate with the treatment. If these instructions are followed, in the majority of cases chronic corticosteroid therapy can be withdrawn by the treating physician, while in rare cases supervision by an endocrinologist is needed.

\section{References}

1. Alves C, Moreira LA.Princípios para a retirada da corticoterapia. Resenha Médica do Hospital São Rafael.1992;1:75-80.

2. Glyn J. The discovery and early use of cortisone. J R Soc Med. 1998;91:513-7.

3. Kountz DS, Clark CL. Safely withdrawing patients from chronic glucocorticoid therapy. Am Fam Physician. 1997; 55:521-5.

4. Chakrabarti P, Wong HY, Scantlebury VP, Jordan ML, Vivas C, Ellis $D$, et al. Outcome after steroid withdrawal in pediatric renal transplant patients receiving tracolimus-based immunossupression. Transplantation. 2000;70:760-4.

5. Hochberg Z, Pacak K, Chrousos GP. Endocrine withdrawal syndromes. Endocr Rev. 2003; 24:523-38. 
6. Krasner AS. Glucocorticoid-induced adrenal insufficiency. JAMA. 1999;282:671-6.

7. Prigent $H$, Maxime V, Annane D. Clinical review: corticotherapy in sepsis. Critical Care. 2004;8:122-9.

8. Rhen T, Cidlowski JA. Anti-inflammatory action of glucocorticoids - new mechanism for old drugs. N Engl J Med. 2005;353: 1711-23.

9. Damiani D, Kuperman H, Dichtchekenian V, Della Manna T, Setian N. Corticoterapia e suas repercussões: a relação custo-benefício. Pediatria (São Paulo). 2001;23:71-82.

10. de Castro M.Efeitos antiinflamatórios e antiproliferativos dos glicocorticóides: concordância ou discordância? Arq Bras Endocrinol Metab. 2005;49:334-6.

11. Cooper MS, Stewart PM. Corticosteroid insufficiency in acutely ill patients. N Engl J Med. 2003;348:727-34.

12. Longui CA. Corticoterapia. In: Monte O, Longui CA, Calliari LE, Kochi C, editores. Endocrinologia para o pediatra. São Paulo: Atheneu; 2006. p.317-24.

13. Brandon DD, Isabelle LM, Samuels MH, Kendall JW, Loriaux DL. Cortisol production rate measurement by stable isotope dilution using gas chromatography-negative ion chemical ionization mass spectrometry. Steroids. 1999;64:372-8.

14. Shulman DI, Palmert MR, Kemp SF; Lawson Wilkins Drug and Therapeutic Committee. Adrenal insufficiency: still a cause of morbidity and death in childhood. Pediatrics. 2007;119:e484-94.

15. Czock D, Keller F, Rasche FM, Haussler U. Pharmacokinetics and pharmacodynamics of systemically administered glucocorticoids. Clin Pharmacokinet. 2005;44:61-98.

16. Lamberts SW, Bruining HA, de Jong FH. Corticosteroid therapy in severe illness. N Engl J Med. 1997;337:1285-92.

17. Laxer RA. Pharmacology and drug therapy. In: Cassidy JT, Petty $\mathrm{RE}$, Laxer RM, Lindsley $\mathrm{CB}$, editors. Textbook of pediatric rheumatology. 5th ed. Philadelphia, PA: Elsevier; 2005. p. 76-141.

18. Faiçal S, Uehara MH. Efeitos sistêmicos e síndrome de retirada em tomadores crônicos de corticosteróides. Rev Ass Med Bras. 1998;44:69-74.

19. Bhattacharyya A, Kaushal K, Tymms DJ, Davis JR. Steroid withdrawal syndrome after successful treatment of Cushing's syndrome: a reminder. Eur J Endocrinol. 2005;153:207-10.

20. Patradoon-Ho P, Gunasekera H, Ryan MM, Ambler GR. Inhaled corticosteroids, adrenal suppression and benign intracranial hypertension. Med J Aust. 2006;185:279-80.

21. Dorin RI, Qualls CR, Crapo LM. Diagnosis of adrenal insufficiency. Ann Intern Med. 2003;139:194-204.

22. da Silva NA, Schiff D. Adrenal insufficiency secondary to glucocortioid withdrawal in patients with brain tumor. Surg Neurol. 2007;67:508-10.

23. Goichot B, Vinzio S, Luca F, Schlienger JL. Do we still have glucocorticoid-induced adrenal insufficiency? Presse Med. 2007; 36:1065-71.

24. Felner EL, Thompson MT, Ratlifff AF, White PC, Dickson BA. Time course of recovery of adrenal function treated for leukemia. J Pediatr. 2000;137:21-4.

25. Vollenweider P, Waeber G. How to plan glucocorticoid withdrawal: diagnostic and therapeutic strategies. Schweiz Rundsch Med Prax. 2003;92:1675-82.

26. Zaloga GP, Marik PM. Hypothalamic-pituitary-adrenal insufficiency. Crit Care Clin. 2001;17:25-41.
27. Arlt W, Allolio B. Adrenal insufficiency. Lancet. 2003;361: 1881-93.

28. Zöllner EW. Hypothalamic-pituitary-adrenal axis suppression in asthmatic children on inhaled corticosteroids: part 1. Which test should be used? Pediatr Allergy Immunol. 2007;18:401-9.

29. Dichtchekenian V. Doenças do córtex adrenal. In: Setian N, editor. Endocrinologia Pediátrica. São Paulo: Sarvier; 2002. p. 374.

30. Margolin L, Cope DK, Bakst-Sisser R, Greenspan J. The steroid withdrawal syndrome: a review of the implications, etiology and treatments. J Pain Symptom Manage. 2007;33:224-8.

31. Amatruda TT Jr, Hollingsworth DR, D'Esopo ND, Upton GV, Bondy PK. A study of the mechanism of the steroid withdrawal syndrome. Evidence for integrity of the hypothalamicpituitary adrenal system. J Clin Endocrinol Metab. 1960;20:339-54.

32. Silva IN, Cunha CF, Finch FL, Colosimo EA. Avaliação da recuperação do eixo hipotalâmicohipofisário-adrenal após corticoterapia por meio do cortisol basal. Arq Bras Endocrinol Metab. 2006;50:118-23.

33. Saracco P, Bertorello N, Faarinasso L, Einaudi S, Barisone E, Altare $\mathrm{F}$, et al. Steroid withdrawal syndrome during steroid tapering in childhood acute lymphoblastic leukemia: a controlled study comparing prednisone versus dexamethasone in induction phase. J Pediatr Hematol Oncol. 2005;27:141-4. Erratum in: J Pediatr Hematol Oncol. 2005;27:242.

34. Stuart FA, Segal TY, Keady S. Adverse psychological effects of corticosteroids in children and adolescents. Arch Dis Child. 2005; $90: 500-6$.

35. Ilowite NT. Current treatment of juvenile rheumatoid arthritis. Pediatrics. 2002;109:109-15.

36. Petty RE, Cassidy JT. Systemic Arthritis. In: Cassidy JT, Petty RE, Laxer RM, Lindsley CB, editors. Textbook of pediatric rheumatology. 5th ed. Philadelphia, PA: Elsevier; 2005. p. 291-303.

37. Axelrod L. Perioperative management of patients treated with glucocorticoids. Endocrinol Metab Clin North Am. 2003;32: 367-83.

38. Graber AL, Ney RL, Nicholson WE, Island DP, Liddle GW. Natural history of pituitary-adrenal recovery following long-term suppression with corticosteroids. J Clin Endocrinol Metab. 1965.25:11-6.

39. Mieure KD, Smith KM, Winstead PS. Supplemental glucocorticoid therapy. Orthopedics.2007;30:116-9.

40. Baid SK, Nieman LK. Therapeutic doses of glucocorticoids: implications for oral medicine. Oral Dis. 2006;12:436-42.

41. Kiess W, Pfaeffle R. Steroid analysis in saliva: a noninvasive tool for pediatric research and clinical practice. J Pediatr (Rio J). 2007; 83:97-9.

42. Silva ML, Mallozi MC, Ferrari GF. Salivary cortisol to assesss the hypothalamic-pituitary adrenal axis in healthy children under 3 years old. J Pediatr (Rio J). 2007;83:121-6.

43. Shah A, Stanhope R, Matthew D. Hazards of pharmacological tests of growth hormone secretion in childhood. BMJ. 1992;304: 173-4.

44. Oelkers W. Adrenal insufficiency. N Engl J Med. 1996;335: 1206-12.

45. Arend EA, Fischer GB, Debiasi M, Schmid H. Inhaled corticosteroid treatment and growth of asthmatic children seen at outpatient clinics. J Pediatr (Rio J). 2006;82:197-203. 
46. Lima JG, Nóbrega LH, Nóbrega ML, Rodrigues AB Jr, Pereira AF. Supressão hipotálamohipófise-adrenal e risco de insuficiência adrenal secundária devido ao uso de dexametasona nasal.Arq Bras Endocrinol Metab. 2002; 46:193-6.

47. Gulliver T, Eid N. Effects of glucocorticoids on the hypothalamic-pituitary axis in children and adults. Immunol Allergy Clin North Am.2005;25:541-55, vii.

48. Kuperman H. Corticoterapia. In: Setian N (ed). Endocrinologia Pediátrica. São Paulo: Sarvier; 2002. p. 404.

49. Deshmukh CT. Minimizing side effects of systemic corticosteroid in children. Indian J Dermatol Venereol Leprol. 2007;73: 218-21.

50. Salem M, Tainsh RE Jr, Bromber J, Loriaux DL, Chernow B. Perioperative glucocorticoid coverage. A reassessment 42 years after emergence of a problem. Ann Surg. 1994;219:416-25.
51. Key SJ, Hodder SC, Davies R, Thomas DW, Thompson S. Perioperative corticosteroid supplementation and dento-alveolar surgery. Dent Update. 2003;30:316-20.

52. Goichot B, Wicky C, Grunenberger F, Schlienger JL. Hypothalamic-pituitary-adrenocortical function during and after steroid therapy: recent data and critical review. Ann Endocrinol (Paris). 2000;61:452-8.

\section{Correspondence:}

\section{Crésio Alves}

Rua Plínio Moscoso, 222/601

CEP 40157-190 - Salvador, BA - Brazil

Tel.: +55 (71) 9178.4055

E-mail: cresio.alves@uol.com.br 